hypertension, blindness, ischemic cardiopathy, moderate aorta stenosis. Scheduled for revision of iliac-femoral bypass of the left leg. expected to last 3 to 6 hours.General anaesthesia and neuraxial anaesthesia weren't the best options, due to patient multimorbidity and aorta's stenosis. With patient's consent, we performed an ultrasound plus nerve stimulation guided lumbar plexus block with Shamrock approach [2] (Stimuplex ultra 360 - $100 \mathrm{~mm}$ - Bbraun) with $30 \mathrm{~m}$ of $0,375 \%$ ropivacaine; subsequently the needle was retracted and further $20 \mathrm{ml}$ of the same mixture were deposited in the plane between psoas and quadratus lomborum muscles. Weak sedation with propofol TCI $0,6 \mu \mathrm{g} / \mathrm{ml}$ was administered.

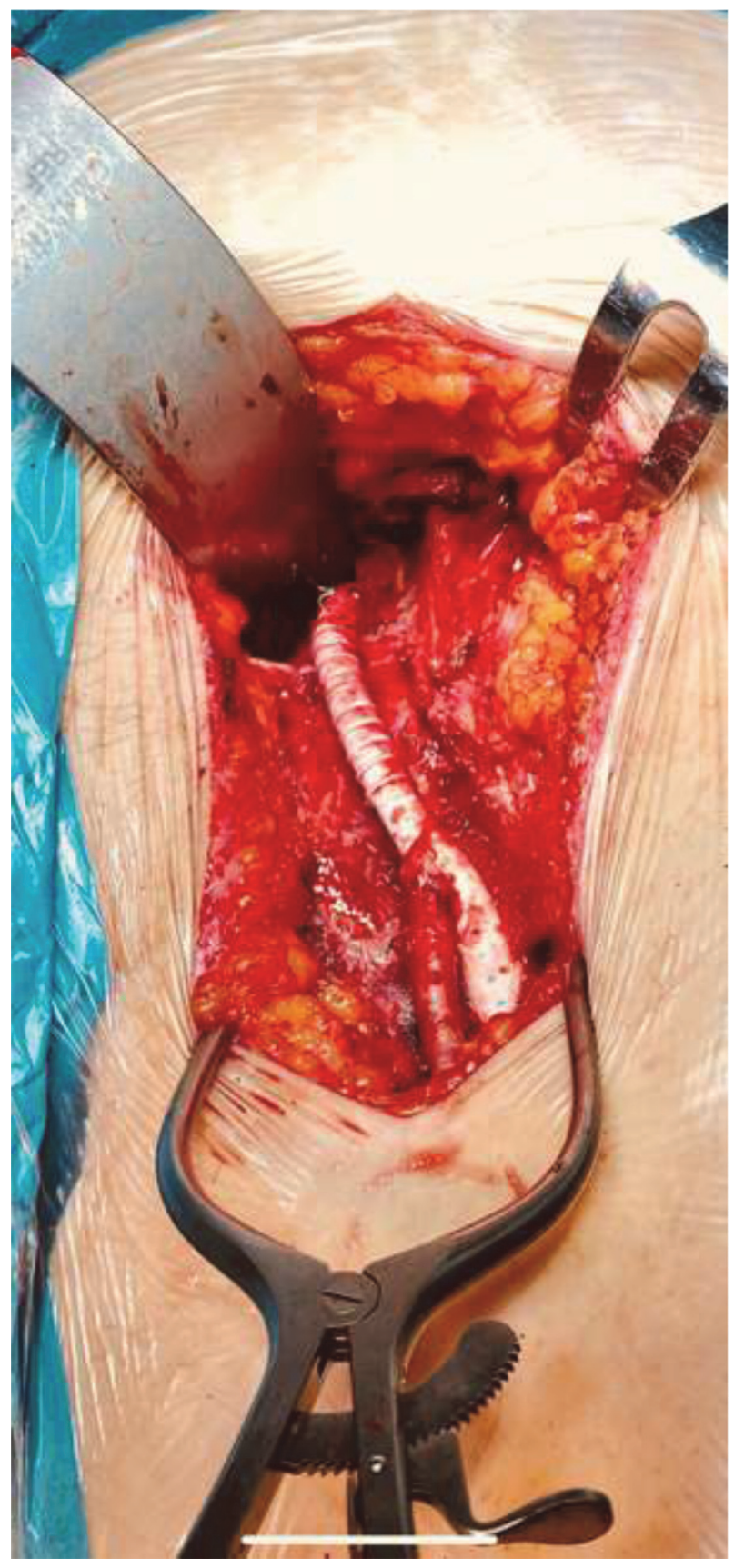

Abstract 199 Figure 2
Results Surgery was carried out in 4 hours with complete surgical anesthesia and hemodynamic stability. After one hour in recovery room, patient was dismissed to the ward.

Conclusions Shamrock approach allowed the successful combination of lumbar plexus and transmuscular quadratus lomborum block

\section{MOTOR SPARING NERVE BLOCKS FOR TOTAL KNEE ARTHROPALSTY (TKA)- IS IT WORTH THE EFFORT?}

F Moosa*, N Sadavarte, N Bedforth. Nottingham University Hospitals NHS Trust, Nottingham, UK

\subsection{6/rapm-2021-ESRA.200}

Background and Aims Anaesthesia and post-operative analgesia for patients undergoing total knee arthroplasty (TKA) has evolved over the last 20 years. Our aim was to carry out a quality improvement project to assess the benefit of motor sparing nerve blocks which includes the IPACK and low femoral triangle blocks ${ }^{1}$. We aimed to assess post-operative pain scores and analgesic requirements ${ }^{2}$.

Methods We carried out a retrospective analysis of patients undergoing TKA including 46 patients after seeking approval from the local audit committee. We used medical notes to obtain patient characteristics, method of anaesthesia and analgesia provision, opiate consumption, and pain scores.

Results $100 \%$ of patients had a spinal anaesthetic with 1 patient requiring conversion to GA. $41 \%$ of patients had a combined IPACK and low femoral triangle block. The remainder received LAI by the surgeon. The mean request for first opiate dose was earlier by $20 \mathrm{~min}$ in the block group. Opiate consumption was significantly lower in the first 24 hours by $21 \mathrm{mg}$ OME. 90\% had no to mild pain at 24 hours in the block group compared to $63 \%$ in the LIA group. Pain scores at 48 hours were similar in both groups. A multimodal approach to analgesia was used for all patients.

Conclusions Motor sparing nerve blocks for patients undergoing TKA is beneficial in the first 24 hours with improved pain scores, reduced opiate consumption as well as surgeon satisfaction. We have implemented recommendations to add these to our ERAS pathway and aim to train anaesthetists in performing these blocks for all TKA patients.

\section{1 'STOP BEFORE YOU BLOCK': RE-AUDIT OF COMPLIANCE AND BREAKING DOWN BARRIERS TO IMPLEMENTATION}

K Malone*, A Newman-Marks, M Molyneux. University Hospitals Bristol and Weston NHS Foundation Trust, Bristol, UK

\subsection{6/rapm-2021-ESRA.201}

Background and Aims Stop Before You Block $(\mathrm{SBYB})^{1}$ is an established initiative to prevent wrong-sided regional anaesthesia (RA). Despite this, compliance with SBYB has been poor in our institution and a recent wrong-sided block ('A Never Event') prompted a re-audit of local processes.

Methods We prospectively examined all unilateral RA performed in a six-week period starting in May 2021. Data on SBYB compliance and risk factors for failing to SBYB were sought. An anonymous online survey was sent out to all anaesthetists regarding SBYB to collect qualitative opinion and 


\section{Stop Before You Block Audit}

Chrissie Gardner <Chrissie.Gardner@uhbw.nhs.uk> Wed 30/06/2021 14:51

To: Katie Malone <km15126@bristolacuk>

Cc: Mat Mobyeux <MatMobneux uhbwnhs.uks ?

Dear Katic

Your audit, Stop Before You Block, has been fully registered on out Audit, Management and Tracking (AMaT) system.

\section{Your project reference is : SURANAES:CA/2021-22/03/SBYB}

Many thanks for registering this important work with the Trust.

BW Chrissie

Q. Ganterer

Ms. Chrissie Gardner

Clinical Autat facilitato

Surgery Head and Neck.

Quality Department

Trust lleadquarters

07983733908

\section{Abstract 201 Figure 1}

Abstract 201 Table 1 SBYB compliance and risk factors for failing to SBYB

\begin{tabular}{|c|c|c|}
\hline Audit Criteria & July 2019 & May/lune 2021 \\
\hline SBYB occurred & $43 \%$ & $82 \%$ \\
\hline WHO Sign In completed & $100 \%$ & $100 \%$ \\
\hline Surgical site marking visible & $100 \%$ & $93 \%$ \\
\hline Patient turned/moved & $29 \%$ & $21 \%$ \\
\hline Distractions present & $0 \%$ & $11 \%$ \\
\hline
\end{tabular}

suggestions for improved SBYB compliance. Local audit committee authorised and registered this work as not needing ethics committee approval.

Results Twenty-eight regional nerve blocks were observed. Risk factors present included surgical site marking not being visible, repositioning of patients and additional distractions (table 1). Although SBYB compliance improved to $82 \%$, in two cases without SBYB there were no risk factors present. Of the 29 survey results received, all agreed a physical reminder needed to be introduced, with posters on ultrasound machines achieving the most favourable response followed by a physical barrier on the syringe.

Conclusions We identified improved compliance in our reaudit, but nearly a fifth of blocks occurred without SBYB. With risk factors for failing to SBYB prevalent including distraction, we suggest a non-user dependent step is needed to improve compliance. We believe this could be achieved if needle manufacturers incorporate a pre-packaged fail-safe barrier into their syringe design or RA needle sheaths.

\section{BILATERAL SUBPECTORAL INTERFASCIAL PLANE BLOCK CATHETERS FOR STERNAL FRACTURES POST CPR}

${ }^{1,2} \mathrm{C}$ Broe* , 'S Mehta, ${ }^{1}$ B Bellew. 'St. Mary's Hospital, London, UK; ${ }^{1}$ Vancouver General Hospital, Vancouver, Canada

\subsection{6/rapm-2021-ESRA.202}

Background and Aims The use of ultrasound to identify fascial tissue layers has led to an increasing number of novel techniques for analgesia of the chest wall. Subpectoral interfascial plane (SIP) blockade is a technique described by Fajardo et al. for ventilation weaning in rib fractures.

Methods A 61-year-old female was admitted to the intensive care unit post cardiac arrest due to major haemorrhage from a degloving scalp laceration. Return of cardiac output was achieved after one cycle of CPR and extubated within 24 hours. Pulmonary rehab proved difficult due to pain from multiple anterior rib \& sternal fractures. Bilateral sternal catheters were inserted day 2 of her admission with loading dose of $40 \mathrm{ml} 0.25 \%$ bupivacaine (1:400,000 adrenaline). Bupivacine $0.125 \%$ local anaesthetic infusions were set at $5 \mathrm{ml} /$ hour with 6 hourly boluses of $20 \mathrm{ml} 0.25 \%$ bupivacaine prescribed as required.

Results A 61-year-old female was admitted to the intensive care unit post cardiac arrest due to major haemorrhage from a degloving scalp laceration. Return of cardiac output was achieved after one cycle of CPR and extubated within 24 hours. Pulmonary rehab proved difficult due to pain from multiple anterior rib \& sternal fractures. Bilateral sternal catheters were inserted day 2 of her admission with a loading dose of $40 \mathrm{ml} 0.25 \%$ bupivacaine (1:400,000 adrenaline). Bupivacine $0.125 \%$ local anaesthetic infusions were set at 5 $\mathrm{ml} /$ hour with 6 hourly boluses of $20 \mathrm{ml} 0.25 \%$ bupivacaine prescribed as required.

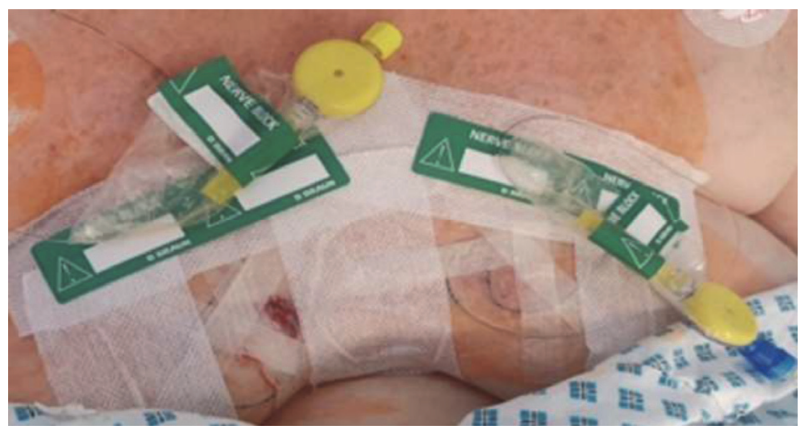

\section{Abstract 202 Figure 1}

Conclusions This case supports the debate that repeated intermittent boluses are required to maintain analgesic efficacy for fascial plane blocks versus continuous local anaesthetic infusion.

\section{A SNAPSHOT SURVEY OF PERIPHERAL NERVE BLOCK USAGE AT A TERTIARY LEVEL CENTRE IN ENGLAND}

${ }^{1} \mathrm{M}$ Moody*, ${ }^{2} \mathrm{~A}$ Spyridoulias, ${ }^{2} \mathrm{~A}$ Vats. ${ }^{1}$ York and Scarborough Teaching Hospitals NHS Foundation Trust, York, UK; ${ }^{2}$ Leeds Teaching Hospitals Trust, Leeds, UK

10.1136/rapm-2021-ESRA.203 